\title{
Augmenting the learning management system of UP Open University
}

\author{
Al Francis D. Librero \\ University of the Philippines Open University, Philippines
}

\begin{abstract}
The University of the Philippines Open University (UPOU) has used Moodle, an open source course management system since 2007. While the application allowed the university to deploy all its courses online, Moodle still presents limitations. The compartmentalised nature of courses within the system inhibits the sharing of learning objects and resources across users. Furthermore, while it does have social networking capabilities to a certain degree (by many accounts more so than other learning management systems), Moodle provides little flexibility when it comes to collaborative learning. Technical issues also hampered the performance of a number of built-in functionalities, which in turn gets in the way of the learning experience. These limitations encouraged facilitators and students alike to opt for third party web applications to fulfil course requirements. This research project aimed to address these limitations by expanding upon the functionalities of Moodle. This was achieved through the installation of modules and plugins within Moodle itself and the integration of external web applications such as conferencing, blogging, e-portfolios and rich media content management through single sign on (SSO). This expansion brought about a number of achievements. First, learning activities were made available which were either new or improved upon what Moodle had by default. This expanded learning management system was piloted with two courses under the Bachelor of Arts in Multimedia Studies programme, which Moodle has been historically ill-equipped to accommodate on its own. Findings of this study were based on the analysis of performance as well as firsthand feedback from users, which in turn is to be used for the continual improvement of UPOU's online course deployment.
\end{abstract}

\section{Introduction}

For the past few years, the University of the Philippines Open University (UPOU) has made use of online course management systems to deploy its courses. It started with the commercial Integrated Virtual Learning Environment (IVLE) and then moved on with Moodle (Modular Object-Oriented Dynamic Learning Environment) in response to the UPOU system's advocacy towards the use of free and open source software. By the time of the migration back in 2007, almost all UPOU courses were deployed online through Moodle. Currently, UPOU offers its courses $100 \%$ online. 


\section{Course management system}

While Moodle is sometimes referred to as a learning management system (LMS), it is not technically accurate to do so. It is more appropriate to refer to Moodle as a course management system. Its core function is to act as an online platform for courses i.e., classrooms on the World Wide Web.

Moodle is widely used with over 53,000 registered active instances all over the world (http:// www.moodle.org). The system owes its popularity to its flexibility, practicality and strong community support. However, there are a handful of underlying limitations hampering Moodle. First and foremost is its compartmentalised nature. The system does not allow for a direct or convenient means of sharing resources across different courses, resulting in unintentional redundancies. This is even more of a problem for integrative courses as communication and attempts to collaborate are not allowed without participants being enrolled across all involved courses. Lastly, while it may not necessarily be a problem for all users, technical issues hamper system performance. This compounds the bandwidth intensive nature of Moodle which subsequently compromises the learning experience.

In order to address these limitations, this study deems to find meaningful ways of expanding the core functionalities of Moodle and come up with an integrated learning management system suited for the needs of UPOU. Furthermore, considering the rather limited resources available to the study, it would also be ideal for this integration to be simple and cost effective to set up.

\section{Multimedia content management system}

Moodle's support for links to external resources has improved through every version upgrade. However, sharing of university-exclusive user generated content across the entire system remains a problem. A viable solution to this is the integration of a separate content management system.

Joomla (http://www.joomla.org) is a popular general content management system (CMS) which is extensively used by UPOU. Through certain extensions, Joomla is able to 1) share a common user database with Moodle, and 2) accommodate uploading and publishing of content from users which can, in turn, be accessed more freely than they would normally be in Moodle. 


\section{E-portfolio system}

An electronic portfolio i.e., e-portfolio, is an organised compilation of artifacts (such as documents, images, video files, podcasts, audio files, slide presentations, spreadsheets, databases, etc.) that demonstrates knowledge, skills, values or achievements and that articulates the relevance, credibility, and meaning of the artifacts being organised and presented (BuzzettoMore, 2010). Compared to traditional portfolios, the nature of an e-portfolio allows more types of media support and is accessible to a much larger audience.

An e-portfolio system allows for a number of benefits on different fronts - possibilities a typical course management system cannot provide (Wilton, 2004).

Students - an e-portfolio system provides students space outside courses they are enrolled in, but still within the university's system. It is used as a means to make sense of academic and even personal expression beyond online classrooms. This helps to further increase the overall learning effectiveness of students and at the same time creates a more holistic learning environment for them. When used in education, e-portfolios are capable of making students more active and meaningful participants in the learning process (Buzzetto-More, 2010).

Faculty - for starters, an e-portfolio can act as an ideal assessment tool for skill-oriented courses where students are evaluated based on their ability to apply what they have learnt throughout their learning process compared to conventional assessment systems like sitting for semester examinations. The benefit of a holistic viewpoint is therefore not limited to students alone.

University/Institution - just like a general content management system, an e-portfolio system can also act as a repository of content exclusive to the university/institution. In other words, an e-portfolio system generates publicity for students and faculty. Should the university/institution deem it necessary, this transparency provides the university/institution opportunity to promote its students as well as its faculty. This exposure of e-portfolios to the outside world, so to speak, is an opportunity for students to showcase their work to their prospective employers, and for the faculty which would like to establish linkages to other organisations.

Mahara (http://www.mahara.org) is an open source e-portfolio system whose popularity has grown over the years due to its improved interface and increased recognition by many institutions that are beginning to focus on using e-portfolios in education. Moodle has also integrated with Mahara with no special bridge required. 


\section{Blogging}

Blogging is a potentially powerful assessment tool. It enables students to express themselves and their learning experience through narratives that teachers and facilitators may not have known otherwise through traditional assessment methods. Moodle supports blogs. Nevertheless, users generally prefer maintaining their own personal blogs and post academic entries there as well. External blogs such as WordPress or Blogger can be integrated directly to Moodle through its repository feature. Users will always have the freedom to use this feature but to have a more concrete link; external blogs can also be embedded within user e-portfolios via really simple syndication (RSS). With this feature, there is a greater opportunity for users to create their own learning stories which could serve as a basis for recognition and accreditation among peers (Schmidt et al., 2009).

\section{Virtual classroom (WiZiQ)}

Distance learning has always been largely conducted asynchronously. However, there are instances where synchronous communication within classes is ideal. There is also evidence that interacting with teachers or facilitators in real-time is favoured by younger learners in UPOU. Moodle has a built-in chat function. The problem is that it is the only synchronous activity supported by Moodle. Due to system limitations of UPOU, this activity is compromised in terms of functionality and hence not reliable.

WiZiQ (http://www.wiziq.com) is a virtual classroom system supporting not just chat, but also audio and video conferencing. Additionally, WiZiQ has a virtual whiteboard with freehand drawing tools. All these functionalities allow for a limited level of collaboration where the designated teacher has full control. Teachers can also make use of the screen-sharing feature to demonstrate computer applications or to show anything in his or her computer desktop to the rest of the class in real-time.

While there are other video conferencing solutions available such as Skype, the main advantage of WiZiQ is that it can actually be directly integrated into Moodle through a plugin. A WiZiQ session can be added to a Moodle course site as an activity, just like forum discussions, quizzes and the like. These sessions can also be recorded. Participants who missed the live session can opt to download the recording and go through exactly what happened using the features supported by WiZiQ.

WiZiQ, however, is not without its weaknesses. As with any other online multimedia software, Internet connectivity is definitely an issue. While online chat requires minimal bandwidth, everything else requires a lot of it, and this can be a problem for any participant without a reliable broadband connection. 


\section{Integration outcomes}

Implementation of the integration of Moodle for pilot testing was carried out in March 2011 for a class of 25 students. This was a photography course under UPOU's Bachelor of Arts in Multimedia Studies programme. A previous offering of the course had already proved that using relevant multimedia resources and tools extensively resulted in increased academic performance and a high level of interaction (Librero, 2010). However, the previous class had not benefited from an augmented Moodle.

Figure 1 shows a framework of integrated systems achieved as of this writing.

There are benefits to experience with this particular integration, as opposed to having all of these components disjointed from each other.

Single sign on - using only one account (or at the very least being under the illusion of having only one account) to access all of these systems is a significant step forward in terms of convenience and consistency.

Improved flow and persistence of native online resources - through Moodle's repository feature, it has become relatively easier to import learning resources. The integrated e-portfolio system, in turn, allows for students to copy resources from within Moodle to his or her respective e-portfolio. For example, if there is a discussion post or maybe an answer to a quiz that he or she is particularly proud of, it can be exported to Mahara. A multimedia content management system can also provide a permanent repository for text, image, audio and video produced through the course and it will still be available for perusal after the course sites or classes have closed at the end of each semester. Keeping blog entries within the respective personal accounts of students and faculty yield the same benefit. 


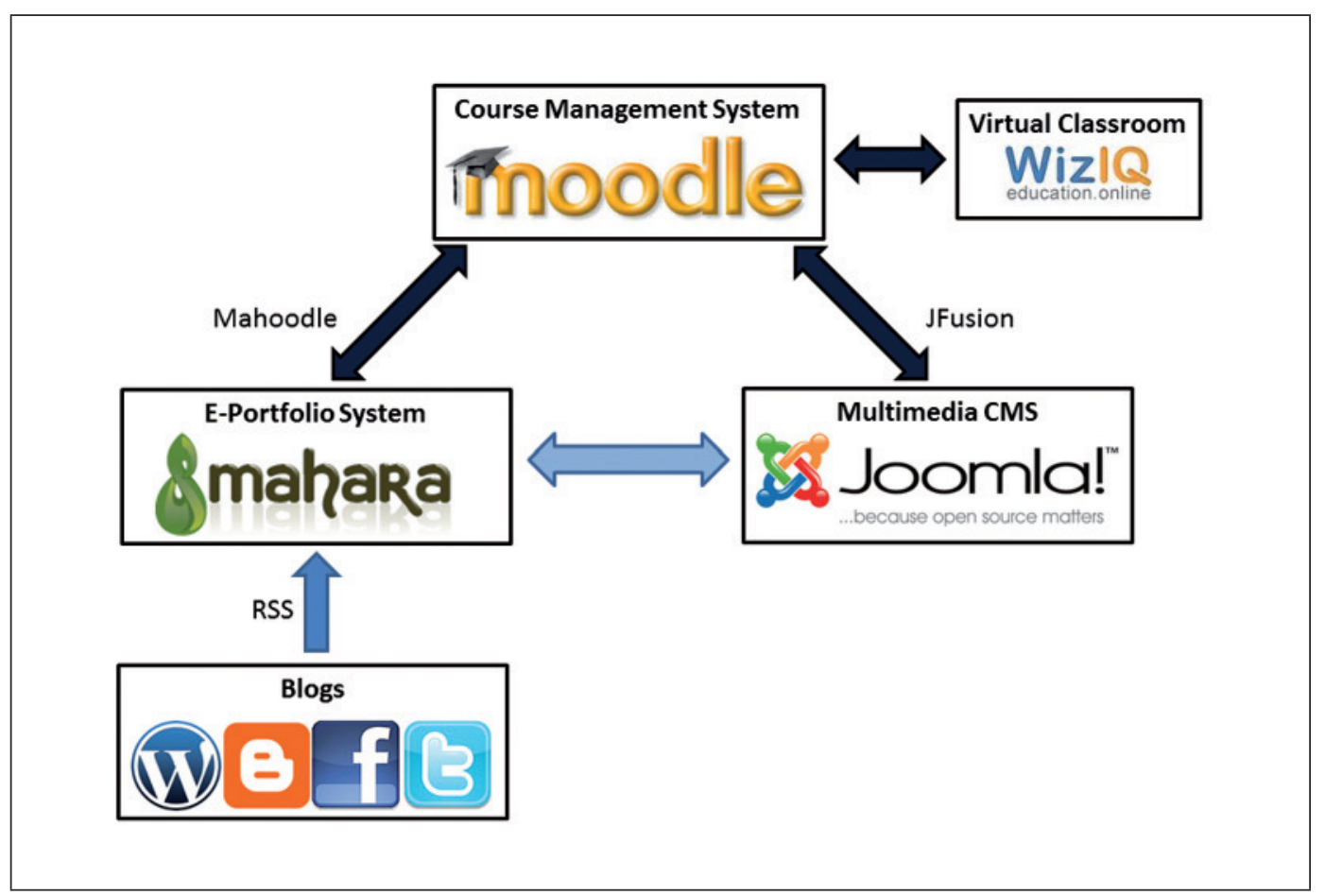

Figure 1 Moodle and other systems integrated to it

Enhanced learning experience - student feedback revealed that virtual classes via WiZiQ was of significant assistance, especially to those who are still not fully acclimated to using Moodle and online learning in general. Students also recognised the value of blogs and e-portfolios as they give them the opportunity to apply what they have learnt in a more practical manner and reveal aspects of what they have learnt which are difficult to assess via conventional examinations or assignments.

Practicality - the implementation of this Moodle integrated system was complicated and costly years ago due to limitations in resources. However, over the years, a lot of open source softwares have been developed and made available for free. Hence, issues pertaining to cost do not hinder the implementation of this integrated system. In relation to this study, the implementation of the Moodle integrated system was conducted by only one person with intermediate technical knowledge. No actual computer programming was performed. The pilot test only required low-cost web hosting. The most expensive component of the implementation is the subscription to WiZiQ. Scalability is only a minor issue, which means that in the event of full implementation within the university, cost increase will only be minimal relative to current expenses in maintaining the main course management system. 


\section{Conclusion and recommendations}

Integrated Moodle system has yield positive results. Students and faculty members involved during the pilot testing period have also expressed their satisfaction and appreciation as far as learning experience and convenience is concerned.

This paper is based on an on-going or long-term project to continuously search for means to augment and improve UPOU's learning management system. However, as of this writing, there are other systems which the university would consider for integration. Among them are the following:

Google Apps - UPOU already uses Google Apps primarily for email, document sharing and secondary course sites. Some users also employ Google Docs for online collaboration. This is a rich tool for learning and other university-related activities. However, there is no concrete integration between UPOU Google Apps and MyPortal (moniker for the university's Moodle instance). UPOU would do well to prioritise this integration.

Second Life - while there is evidence showing the decline of this once popular virtual world, there is still potential in Second Life as a learning tool. There have already been efforts to integrate the virtual world with Moodle. However, development has apparently halted, and the plugin does not support the latest version of Moodle.

Mobile Learning and Support - Internet connectivity is an issue in many parts of the Philippines. Nevertheless, people from the far reaches of the archipelago own and use mobile phones. UPOU must explore available mobile platforms and find means to integrate them with the learning management system to increase coverage and speed up communication.

Al Francis D. Librero is in the Faculty of Information and Communication Studies, University of the Philippines Open University, Barangay Maahas, Los Baños, Laguna, Philippines. Email: alfrancis.librero@upou.edu.ph

\section{References}

Backer, E.M. (2011). Validation of competencies in e-portfolios: a qualitative analysis. Retrieved from http://www.irrodl.org/index.php/irrodl/article/view/893/1769.

Brandes, G.M. \& N. Boskic. (2008). Eportfolios: from description to analysis. Retrieved from http://www.irrodl.org/index.php/irrodl/article/view/502/1050.

Brown, J.O. (2011). Dwell in possibility: PLAR and e-portfolios in the age of information and communication technologies. Retrieved from http://www.irrodl.org/index.php/irrodl/ article/view/917/1767 
Augmenting the learning management system of UP Open University

Buzzetto-More, N. (2010). The E-Portfolio Paradigm: Informing, Educating, Assessing, and Managing With E-Portfolios. Santa Rosa (California): Informing Science Press.

Librero, A.F.D. (2010). Implementing an online photography course at the UP Open University: converging ICTs to enhance student learning outcomes and achievements. Asian Association of Open Universities Journal, 5(2), 103-112.

Schmidt, J.P., C. Geith, S. Haklev \& J. Thierstein. (2009). Peer-to-peer recognition of learning in open education. Retrieved from http://www.irrodl.org/index.php/irrodl/article/ view/641/1392 on 31 July 2001.

Wilton, D. (2004). Benefits of an eportfolio. Retrieved from http://www.danwilton.com/ eportfolios/benefits.php on 29 May 2011. 